\title{
IMAGENS, CORES E MÚSICA: O HAICAI DE ALICE RUIZ NA SALA DE AULA
}

\section{IMAGES, COLORS AND MUSIC: ALICE RUIZ'S HAICAI IN THE CLASSROOM}

\begin{abstract}
Hélder Pinheiro*
Marivaldo Omena Batista**

Resumo:O presente artigo apresenta uma experiência de leitura com os haicais de Alice Ruiz em uma turma do $1^{\circ}$ ano do ensino médio. A experiência foi realizada em uma escola da rede pública da cidade de Maceió-Alagoas, com a colaboração de 27 alunos, sendo que 19 estudantes tiveram uma participação mais ativa. Para a incursão da poesia no âmbito escolar, procuramos elaborar um fazer pedagógico calcado em algumas premissas do Método Recepcional, de Aguiar e Bordini (1993). No que concerne aos estudos em torno do haicai de Alice Ruiz, apresentamos uma perspectiva crítica e analítica. Analisamos alguns poemas sob o ponto de vista da estilística de Cohen (1974) e de Staiger (1975), chamando a atenção para alguns aspectos formais da obra e o sentido que assumem. Por fim, discutimos a recepção e a experiência de leitura em sala de aula. Desse modo, os resultados obtidos em nossa pesquisa mostram estudantes mais interessados na leitura de poesia em sala de aula, participativos e perceptivos no que se refere às questões estéticas e temáticas de alguns poemas da Alice Ruiz.

Palavras-chave: Haicai. Alice Ruiz. Recepção. Experiência de leitura.

Abstract:The present article presents a reading experience with the haiku of Alice Ruiz in a class of the first year of high school. The experiment was carried out in a public school in the city of Maceió-Alagoas, with the collaboration of 27 students, with 19 students having a more active participation. For the incursion of poetry in the school context, we try to elaborate a pedagogical work based on some premises of the Receptive Method, by Aguiar and Bordini (1993). With regard to the studies on Alice Ruiz's haiku, we present a critical and analytical perspective. We analyze some poems from the point of view of the stylistics of Cohen (1974) and Staiger (1975), drawing attention to some formal aspects of the work and the meaning they assume. Finally, we discussed the reception and the reading experience in the classroom. Thus, the results obtained in our research show students more interested in reading poetry in the classroom, participatory and perceptive about the aesthetic and thematic issues of some Alice Ruiz poems.
\end{abstract}

Keywords: Haicai. Alice Ruiz. Reception. Reading experience

\section{Introdução}

O trabalho com o haicai na sala de aula possibilita ao professor experimentar alguns percursos metodológicos significativos, o que pode contribuir para uma experiência de leitura literária. Centrado, quase sempre, na percepção dos aspectos da natureza, através da leitura desta forma lírica, podemos perceber as cores, as imagens poéticas e a musicalidade dos versos - que são configurados através de dois de cinco sílabas e de uma redondilha maior. O haicai, como gênero poético, surgiu no Japão e tem como principais expoentes os poetas Bashô, Buson, Issa e Shiki, que, de acordo com Gebara (2012), contribuíram para a elaboração estética do haicai, bem como a sua função e o tratamento temático.

No que se refere ao viés temático, o haicai aborda a natureza. O fazer poético de Alice Ruiz, a título de exemplo, aproxima-se deste tratamento temático, já que a sua poesia se apropria da imagem da noite, das estações do ano, dos pequenos animais e dos

\footnotetext{
* Professor Titular em Literatura Brasileira na Universidade Federal de Campina Grande e do Programa de Pós Graduação em Linguagem e Ensino. helder.pinalves@ gmail.com

${ }^{* *}$ Mestre em Linguagem e Ensino pela Universidade Federal de Campina Grande. mobj-de88@hotmail.com
} 
insetos. Dessa maneira, a incursão da temática da natureza nos haicais da poetisa, de acordo com Marques (2012), é projetada por meio de um Princípio de Shasei e Shiki ${ }^{1}$

Com efeito, o princípio de Shasei, conforme Marques (2012, p.80), consiste que o haicai deve ser descritivo, isto é, elaborado a partir da observação de uma cena. Dessa forma, este gênero não apresenta uma subjetividade em torno da cena capturada; no entanto, projeta a observação da natureza flagrada ao vivo por meio da linguagem poética.

Já o princípio de Shiki, ainda em consonância com Marques (2012), é uma perspectiva filosófica oriental que sugere ao poeta esquecer-se de si mesmo, a fim de que o haicaísta se torne parte da própria natureza, como se ele mesmo estivesse inserido na cena contemplada. Sendo assim, esta função da não subjetividade é o que, conforme Gebara (2012), denomina-se como Zen. Shiki enfatiza, por esse viés, que o referido pensamento oriental "sugere que os haicais sejam escritos enquanto se observa diretamente a cena, e não de memória, porque isto pode distorcer os elementos da cena" (MARQUES, 2012, p.81).

No Brasil, o gênero teve uma relevante adaptação. De acordo com Goga (1988), Afrânio Peixoto, em 1919, introduziu o haicai a partir da obra Trovas populares brasileiras. Gebara (2012), por sua vez, comenta que Peixoto expõe algumas adaptações no prefácio de seu livro. Dessa forma, uma das principais adequações se dá pela língua, pela configuração fônica do haicai e pelo tratamento temático. A vivência com a língua portuguesa contribuiu para que os imigrantes japoneses do início do século XX pudessem experimentar estes novos códigos linguísticos, assim como a contemplação da fauna e da flora brasileira, as quais foram incorporadas no viés temático do haicai.

Para os limites deste artigo escolhemos a temática da natureza de alguns haicais de Alice Ruiz. A abordagem se divide em dois blocos: no primeiro, relacionamos sete haicais da referida poetisa, a fim de iniciar a nossa vivência com a leitura poética através do Princípio de Shasei e Shiki; no segundo momento, uma indicação de procedimentos metodológicos possíveis de serem utilizados no âmbito escolar.

Estas sugestões metodológicas surgiram a partir da pesquisa que desenvolvemos no programa de Pós-Graduação em Linguagem e Ensino (PÓSLE), pela Universidade Federal de Campina Grande (UFCG), cujo título foi: A poesia de Alice Ruiz: entre a prática de leitura e a recepção ${ }^{2}$. Estas práticas foram inspiradas através de algumas categorias do Método Recepcional de Aguiar e Bordini (1993) e da Estética da Recepção de Hans Robert Jaus (1994); Wolfgang Iser (1979); (1995), o que favoreceu a uma convivência com a poética de Alice Ruiz na escola, bem como a experiência estética em sala de aula.

Passemos, a seguir, a uma discussão em torno da produção poética de Alice Ruiz. Posteriormente, a leitura dos haicais a partir de um viés analítico e teórico, a fim de apontar algumas características estéticas e temáticas dos haicais selecionados.

\footnotetext{
${ }^{1}$ Masaoka Shiki, ou melhor, Masaoka Tsunenori, nasceu em 17 de setembro de 1867 em Matsuyama, e morreu em 19 de setembro de 1902, em Tokyo. Quando criança, Shiki era chamado Tokoronosuk e na adolescência, seu nome mudou para Noboru. Sua Mãe, Yae, era professora. Ainda na escola primária, Shiki começou a escrever prosa e poesia. Foi poeta, crítico, jornalista e ensaísta, fundador da revista literária japonesa "Hototogisu" e patrono de uma série de jovens poetas, que desempenhou um papel de liderança no relacionamento do waka e formas tradicionais da poesia japonesa como o haicai. Durante sua curta vida, ele se tornou um crítico muito estimado. Seu papel como figura carismática literária complementou seus méritos como poeta e cronista (CLEMENT, 2011 Apud MARQUES, 2012, p.80).

${ }^{2}$ A dissertação A poesia de Alice Ruiz: entre a prática de leitura e a recepção, de Marivaldo Omena Batista (2016), foi orientada pelo Prof. Dr. José Helder Pinheiro Alves.
} 


\section{Produção poética de Alice Ruiz}

Nascida em 22 de janeiro de 1946, a poetisa curitibana Alice Ruiz estreou o seu percurso literário com a obra Navalha na liga (1980). É um livro significativo no que diz respeito a um caminho estético e discursivo feminista. Conforme Murgel (2010), a obra é composta de poemas produzidos em meados dos anos de 1970, que contemplam as questões feministas de forma consistente. Posteriormente, vieram Paixão xama paixão (1983), Pelos pelos (1984), HAI-TROPIKAI (1985), Rimagens (1985), Vice versos (1988), Desorientais (1996), HAIKAIS (1998), Poesia pra tocar no rádio (1999), YUUKA (2004), Salada de frutas (2008), Conversa de passarinhos (2008), Dois em um (2008), Três linhas (2009), Boa companhia (2009), Nuvem feliz. (2010), Jardim de haijin (2010), Proesias (2010), Dois Haikais (2011), Estação dos bichos (2011), Luminares (2012) e Outro silêncio (2015).

A primeira obra a que tivemos acesso para a elaboração da pesquisa foi o livro Dois em um $^{3}$ (2008), que contempla seis obras poéticas de Alice Ruiz publicadas em meados dos anos de 1980. Na antologia, há traços estéticos peculiares ao seu período de produção que perduraram as suas atuais composições. No que concerne aos elementos estéticos, podemos citar os recursos imagéticos e sonoros. Na perspectiva temática, os poemas expressam um caráter reflexivo no que diz respeito às condições femininas, às questões sentimentais e à natureza.

As leituras posteriores de Conversa de Passarinhos (2008), Jardim de Haijin (2010) e Outro silêncio (2015) revelam ao leitor uma linguagem poética calcada no haicai ${ }^{4}$. A partir de três versos poéticos, percebemos o olhar do observador, que contempla a natureza de maneira precisa e sensível. Nos haicais de Alice Ruiz, podemos perceber o apreciar das estações do ano através de uma poeticidade sutil, cujas imagens mais recorrentes são a lua, as estrelas, as folhas primaveris, os vaga-lumes, o mar e os rios.

Por meio de uma leitura analítica, apreciamos aqui os elementos estéticos mais recorrentes no fazer poético de Ruiz, visando construir uma visão mais orgânica ${ }^{5}$ de sua escrita. A maioria dos haicais que foi apresentada na análise foi contemplada na experiência literária em sala de aula, tais como: "Pipa perdida" (2010), "chuva de folhas" (2010), "Navalha na liga" (2008); já outros nos auxiliaram a investigar a linguagem poética de Alice Ruiz, como, por exemplo, "Silêncio na mata" (2015), "Noite de lua cheia" (2015), "Céu fechado" (2015) e "Vontade de ficar sozinha" $(2008)^{6}$.

\footnotetext{
${ }^{3}$ O livro Dois em um (2008) - assim como alguns poemas aqui escolhidos para a análise, por apresentarem elementos estéticos em comum - foi contemplado em nossa pesquisa por ser uma obra que está inserida no PNBE (Programa Nacional Biblioteca na Escola) de 2011; no entanto, a escola, onde foi realizada a nossa experiência de leitura literária, não oferece este exemplar na biblioteca. Conteúdo do PNBE disponível no site: http://portal.mec.gov.br/index.php?option=com_docman\&view=download\&alias=13914-pnbe-2011-sebpdf\&category_slug=agosto-2013-pdf\&Itemid=30192

${ }^{4}$ Ruiz S (2010, p.9) comenta que o haicai "se faz com três linhas, ou versos, e não é mais de 17 sílabas. Seu tema é a natureza, e não nossos sentimentos e pensamentos. Se faz com simplicidade, leveza, desapego, sutileza, objetividade, integração com o todo".

${ }^{5}$ Entende-se por orgânico tudo aquilo que é composto de elementos estéticos que fomentam a composição do poema. Para isto, Cohen (1974), ao se apropriar de Saussure, compara a poesia ao signo verbal. Dessa forma, o poema possui significado e significante. Por meio dessa analogia, justifica-se como se dá o processo orgânico do poema: imagem, som e discurso.

${ }^{6}$ Estes poemas selecionados em nossa analise foram escolhidos por apresentarem um elemento estético em comum: o signo da pausa natural.
} 
As obras Dois em um (2008), Conversa de passarinhos (2008), Jardim de Haijin (2010) e Outro silêncio (2015) apresentam um elemento estético significativo em sua composição poética: o signo da pausa natural. Em Estrutura da linguagem poética, Cohen (1974) comenta que a pausa natural, ou o silêncio, é o espaço em branco do poema, que representaria a ausência de voz. Dessa forma, o signo da pausa natural é a ausência de sinais de pontuação gramatical, tais como: vírgula, ponto final e reticências.

A relevância de estudar o signo natural da pausa na poesia de Alice Ruiz está no seu constante uso. $\mathrm{O}$ silêncio é um recurso estético peculiar à composição poética moderna desde os meados do século XIX na literatura ocidental. Cohen (1974, p.53) comenta que "essa recusa de pontuação foi encarada como uma extravagância da parte do poeta, mas devemos desconfiar de explicações semelhantes quando se trata de um fenômeno tão generalizado". É por esse sentido que procuramos fundamentar o signo da pausa natural no trabalho poético de Alice Ruiz, o que corrobora a relevância deste recurso estético para a construção imagética do haicai.

\title{
2 Um espaço chamado cor, imagem e silêncio: haicai
}

Alguns haicais de Alice Ruiz apresentam nuances que se distanciam da poesia japonesa, como, por exemplo, a presença de um eu lírico. De acordo com Andrade e Cardoso (2012), esta especificidade lírica é chamada de Poetrix. Para uma compreensão significativa desta especificidade, iniciamos o percurso analítico a partir das leituras dos haicais "Silêncio na mata" (2015), "Noite de lua cheia" (2015), "Céu fechado" (2015) e "Nada na barriga" (2008), a fim de estudar como se dá a configuração estética e estilística da poesia de Alice Ruiz. O haicai "Silêncio na mata" observa silenciosamente a singularidade e a simplicidade da natureza. Para isso, percebemos uma organização estética que evidencia a cena contemplada pelo observador.

\author{
Silêncio na mata \\ A mariposa pousa na flor \\ Outro silêncio
}

(RUIZ, 2015, p.25)

O haicai "silêncio na mata" (2015) apresenta o signo da pausa natural acentuando a figura da gradação, cuja disponibilidade das ações é constituída em sequência. O primeiro verso (silêncio na mata) se refere "a uma imagem estática" (RUIZ, 2015, p.6), isto é, uma cena da natureza que está sendo contemplada pelo observador. O segundo verso (A mariposa pousa na flor) ressalta uma ação e o último verso (outro silêncio) revela o desfecho da cena. Em contrapartida, uma questão que nos inquieta: como o efeito da gradação se configura esteticamente no haicai?

Por meio da leitura em prosa do poema ${ }^{7}$, percebemos a omissão dos signos estéticos de pontuação responsáveis pelo efeito da pausa semântica e de alguns conectivos que ligam uma ação à outra. Dessa maneira, lê-se "Silêncio na mata e, de repente, a mariposa pousa na flor e, consequentemente, outro silêncio". A partir desse viés, o signo da pausa natural, que é a ausência de qualquer elemento estético de

\footnotetext{
${ }^{7}$ A leitura em prosa do poema é um meio de análise em que Cohen (1974), em Estrutura da linguagem poética, utiliza para evidenciar uma figura retórica ou fônica de um verso poético. No entanto, o estudioso não sintetiza o verso a fim de resumi-lo, retirando de sua tessitura os elementos estéticos do poema, mas transforma o texto poético em prosa para demarcar, na sua leitura, os componentes estéticos e estilísticos que compõem o poema.
} 
pontuação semântica, e o assíndeto evidenciam o efeito da gradação nas cenas, tornando o ritmo da imagem dinâmico para o leitor.

A homofonia interna, por meio da aliteração do $/ s /$ e da homofonia semântica (a rima mariposa/pousa), sugerem a alusão do som das asas da "mariposa" durante o voo. No entanto, o signo da pausa no último verso do poema prolonga o efeito do silêncio após o pouso da mariposa na flor, sugerindo o som do "silêncio na mata". Cohen (1974) comenta que os elementos estéticos que determinam a figura do som nos textos poéticos, tais como: a pausa, a rima, a assonância, a aliteração, a paranomásia e o paralelismo sintático são constituídos através da homofonia semântica, da homofonia interna e do signo da pausa. Desse modo, o poema adquire dicção e melodia.

Por meio desses elementos estéticos, percebemos uma organização que evidencia o princípio de Shasei, já que o referido haicai apresenta uma descrição da cena da natureza. Esse processo, que torna o ato de contemplar a natureza inteligível, é manifestado através da configuração da linguagem.

O haicai "Noite de lua cheia" (2015) apresenta o símbolo nictomórfico - lua cheia -, que pode sugerir, na leitura do poema, um tipo de erotismo. A disposição erótica do haicai pode ser evidenciada a partir de alguns elementos estilísticos e estéticos. Desse modo,

Noite de lua cheia

Dentro do céu nublado

Ainda incendeia

(2015, p.59)

O epíteto nominal (de lua cheia) sugere uma noite vistosa, em que há feixes de luz e um intenso brilho da lua cheia dentro do céu nublado. Nesse sentido, mesmo coberta de nuvens, a lua incendeia a noite. O símbolo nictomórfico (lua cheia) pode expressar um sentido erótico, uma vez que a lua cheia esteja relacionada à figura da mulher. Marques (2012, p81) comenta que a figura lunar é um símbolo feminino por apresentar ciclos. No poema, o elemento estético "lua cheia" estaria enfatizando o período fértil, cujo significado da sensibilidade da libido estivesse evidenciado pela homofonia externa (cheialincendeia).

No sentido estilístico, o signo natural está atuando na marcação do hipérbato. Dessa forma, observamos que, na leitura em prosa do haicai "Noite de lua cheia ainda incendeia dentro do céu nublado", a figura de inversão justifica o movimento da imagem do brilho da lua dentro das nuvens. Com efeito, a expressão "ainda incendeia" sugere à permanência da capacidade de queimar. Sendo assim, o sujeito lírico observa e descreve a disposição erótica da lua cheia, que, mesmo escondida dentro das nuvens, dissemina todo o seu brilho.

Em "O céu fechado", o símbolo nictomórfico - lua - está personificado, já que a tessitura do texto resignifica o signo lunar através da linguagem poética, atribuindolhe um valor equivalente à figura da mulher.

Céu fechado

A lua vestida de nuvens

Se insinua

(RUIZ, 2015, p.59)

O sujeito lírico cria uma imagem lunar que confere o erotismo, uma vez que o haicai apresenta uma escolha lexical pertinente a esta disposição. Os elementos 
moduladores vestida e insinua atribuem ao símbolo nictomórfico uma característica humana, em que a imagem da lua se transfigura, caracterizando-se na representação da lubricidade feminina.

A imagem Céu fechado expressa uma circunstância, em que o sujeito lírico contempla e descreve a cena. No segundo verso, ao observar a lua coberta de nuvens, o sujeito lírico aprecia a figura lunar de modo conotativo. Esta percepção estética se dá por meio do desvio semântico, isto é, o epíteto adnominal vestida de nuvens. No terceiro verso, o eu lírico comenta a disposição da lua de insinuar sua beleza vestida de nuvens, sugerindo, por sua vez, a imagem de uma mulher, que se insinua coberta por um vestido.

$\mathrm{Na}$ perspectiva estilística, o signo da pausa natural evidencia a figura do hipérbato, o que provoca no leitor o efeito de o estranhamento na apreciação do poema. Na leitura em prosa de o haicai "A lua vestida de nuvens se insinua no céu fechado", observamos que a opacidade da estrutura de sentido do texto não sobressaiu, já que não há a figura da inversão destacando algumas expressões significativas para a compreensão do poema.

No entanto, a estrutura sintática do poema não é apenas o único elemento estético contemplado, já que a inversão realça outros objetos estéticos, como, por exemplo, a figura lunar personificada. Desse modo, o segundo verso (A lua vestida de nuvens) provoca um efeito de desvio semântico, visto que o sentido da "lua" é ressignificado, atribuindo-lhe características humanas e eróticas, uma vez que se insinua vestida de nuvens no céu fechado.

O signo da pausa natural evidencia os recursos imagéticos e sonoros no haicai "Nada na barriga". Além de atuar na composição estrutural do poema, a pausa natural é um elemento estilístico que colabora para a construção de um discurso poético.

Nada na barriga
Navalha na liga
Valha

(RUIZ, 2008, p.156)

O poema "Nada na barriga" é configurado em um modelo de haicai, cujo som sugere a reprodução de uma navalhada a partir das homofonias internas, a aliteração $/ n /$, $/ l h /, / v /$, a assonância $/ a /, / i /$. No que se refere à rima (barriga/liga, navalhada/valha), percebemos a figura da inconsequência. Conforme Cohen (1974), esta figura é constituída por meio da homofonia desprovida de significante. Dessa forma,

pareceria normal satisfazer às exigências da rima valendo-se das homofonias semânticas. Existem, de fato, dois tipos de homofonia. A primeira [...] rege as palavras simples. Baseada na contingência da língua, é desprovida de sentidos: por exemplo, "abrigo-trigo", "condor-dor", etc. [...] (COHEN, 1974, p.68).

Desse modo, a figura da inconsequência pode reforçar a leitura rítmica e melódica do poema, que pode sugerir para o leitor o som de uma navalhada. Em uma entrevista concebida à pesquisadora Murgel $(2010)^{8}$, Alice Ruiz apresenta a "navalha na

\footnotetext{
${ }^{8}$ Entrevista concebida à pesquisadora Ana Carolina Arruda de Toledo Murgel para a produção de sua tese de doutorado "'Navalhanaliga': a poética feminista de Alice Ruiz", pela Universidade Estadual de Campinas. Conteúdo disponível em: http://caromurgel.mpbnet.com.br/artigos/MURGEL_Ana_Carolinatese.pdf
} 
liga" como um tipo de recurso de segurança das prostitutas. A partir desse viés, percebemos uma construção imagética e sonora associada a uma questão social, cuja imagem nada na barriga pode sugerir o significado da fome. Sendo assim, a poetisa comenta, ainda na entrevista, que a condição da fome seria a única justificativa válida para uma mulher se submeter à prostituição. Com efeito, este Poetrix potencializa ${ }^{9}$ discussões em torno de temas significativos, nos quais podem afetar o leitor de maneira sensível e discursivo.

Com efeito, Alice Ruiz lança mão de um tipo signo que é reconte em sua poesia: a pausa natural. Este elemento estético evidencia alguns recursos formadores de imagem e som nos haicais. Através do silêncio, as cores da natureza e o som que a mesma pode produzir são projetados nos haicais. Feita esta leitura crítica de alguns aspectos formais e semânticos da obra, passemos à experiência em sala de aula.

\section{Experiência com os haicais em sala de aula}

A experiência de leitura com os haicais em sala de aula foi realizada em uma escola de Rede Pública de ensino na cidade de Maceió - AL (Escola Benedito de Moraes) com alunos do $1^{\circ}$ ano "B" do Ensino Médio. As atividades desenvolvidas em sala de aula tiveram como foco observar a recepção de leitura dos discentes. A escolha do público parte de um pressuposto de que esses alunos não tiveram um contato significativo com o texto poético, no sentido de vivência e experiência de leitura. Para exemplificar as estratégias que utilizamos nesta experiência com a leitura dos haicais de Alice Ruiz, segue abaixo uma tabela que ilustra as etapas que seguimos em sala de aula:

\begin{tabular}{|ccc|}
\hline Conteúdo & $\begin{array}{c}\text { Material didático } \\
\text { Antologia dos haicais de } \\
\text { Alice Ruiz }\end{array}$ & $\begin{array}{c}\text { Estratégias } \\
\text { Haicais de Alice Ruiz }\end{array}$ \\
\hline & Lápis de cor & Leitura oral \\
\hline & Resma de papel A4 & $\begin{array}{c}\text { Leitura } \\
\text { compartilhada }\end{array}$ \\
\hline
\end{tabular}

Para dar início à experiência, observamos a estrutura física da escola, como, por exemplo, a sala de aula, o auditório e a biblioteca. A preocupação com o espaço de leitura na escola se dá pelo fato de ser o lugar onde a leitura é negociada e compartilhada.

Em Aspectos metodológicos do ensino de literatura, Rouxel (2013) põe a sala de aula em uma condição de personagem significativa para a mediação da leitura literária, uma vez que o espaço de leitura é o lugar onde comporta a metodologia do professor, a leitura do texto literário e o debate das múltiplas interpretações dos estudantes. Desse modo,

A sala de aula representa assim o papel de regular. Ela é o espaço intersubjetivo onde se confrontam os diversos "textos de leitores", a fim de estabelecer o texto do grupo, objeto se não de uma negociação,

\footnotetext{
${ }^{9}$ Potencializar, de acordo com Spinoza (apud KLINGER, 2014, p.70), sugere a literatura, ou o discurso, pode afetar e ser afetado pelo leitor.
} 
ao menos de um consenso. A presença da turma é essencial na formação dos jovens leitores: lugar de debate interpretativo (metamorfose do conflito de interpretação), ela ilumina a polissemia dos textos literários e a diversidade dos investimentos subjetivos que autoriza (ROUXEL, 2013, p.23).

Por fim, procuramos assistir algumas aulas da disciplina de Língua Portuguesa na turma do $1^{\circ}$ ano B. A sala de aula era quente, havia apenas dois ventiladores pequenos para atender uma turma de 27 alunos. Constatamos, também, muito barulho que vinha de fora da escola, tais como: o som de britadeira ${ }^{10}$ e o barulho de carros e motos que passavam com frequência nas ruas transversais ao colégio. Durante as observações da aula, percebemos uma turma desmotivada e uma metodologia de ensino calcada em um modelo tradicional, o qual se centrava apenas no livro didático.

Para coletar os dados, aplicamos um questionário ${ }^{11}$ para sondar os horizontes de expectativas dos estudantes e a gravação em áudio das aulas.

No que concerne à análise do questionário de sondagem, destacamos três perguntas relevantes à nossa experiência:

1. Você gosta de ler?

2. Você gosta de poesia?

3. Você gosta de leitura em voz alta?

Na questão um (01), procuramos sondar se os participantes da experiência se consideram leitores. Dessa forma, perguntamos: "Você gosta de ler? Justifique". Com efeito, organizamos os dados obtidos em um gráfico.

\section{Gráfico 1}

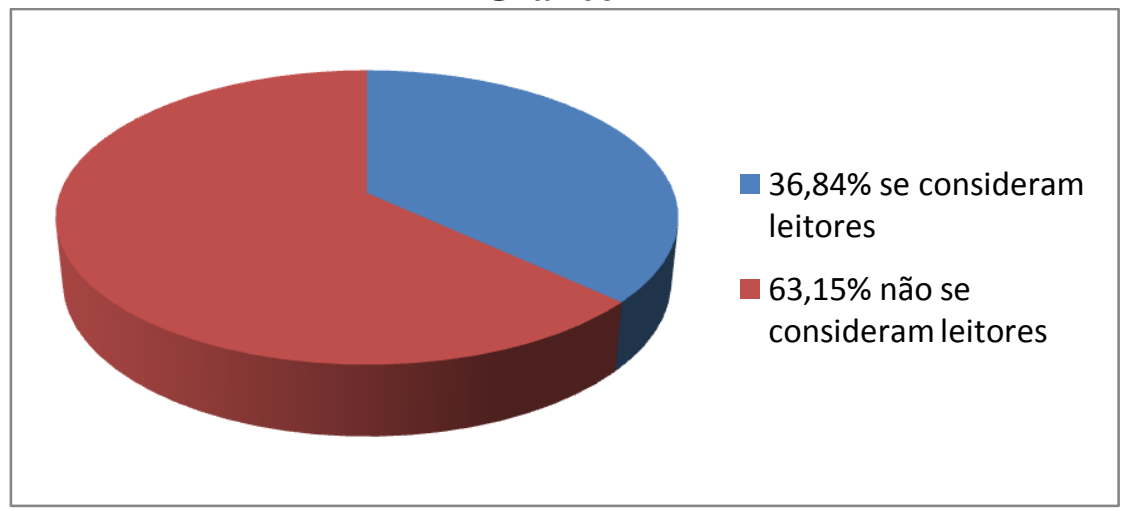

Em seguida, mencionamos alguns comentários dos discentes a respeito desta questão.

M01: Sim, porque aprimora mais o meu conhecimento.

M02: Sim. Porque se lê aprende palavras novas e coisas novas também.

\footnotetext{
${ }^{10}$ É um tipo de máquina que tem como finalidade quebrar pavimentos de rua ou asfaltos a fim de restaurá-los.

${ }^{11}$ Entendemos os questionários de sondagem como um instrumento de coleta de dados. Dessa forma, consideramos que são "documentos que contêm um número de perguntas às quais os respondentes terão que responder. Eles talvez terão que marcar nos espaços, escrever opiniões ou colocar as opções em ordem de importância. O ponto importante é que o pesquisador normalmente não está presente quando o questionário está sendo preenchido" (MOREIRA, CALEFFE, 2006, p.85).
} 
M03: Sim. Livros interessantes e porque ajuda no aprendizado.

M04: Sim, porque faz bem para minha vida.

M05: Gosto, porque ler desenvolve o pensamento.

M12: Mais ou menos, gosto e ler as coisas que me interessa.

Constatamos que $36,84 \%$ dos estudantes ${ }^{12}$ se consideram leitores. Embora suas concepções de leitura estejam direcionadas a várias perspectivas, a maioria desses alunos comentou que a leitura desenvolve o pensamento. Ao atentarmos para o relato de M05 (Gosto, porque desenvolve o pensamento), percebemos um argumento consciente a repeito do poder da leitura para o desenvolvimento inteligível do indivíduo. No contexto da leitura de poesia, Rouxel (2013) comenta que a experiência de leitura amplia a sensibilidade do leitor, no sentido de enriquecer sua personalidade e sua postura crítica diante do texto literário e do mundo.

Ao mencionar que a leitura "faz bem para minha vida", M04 cita a importância do texto para a formação do ser. Dessa maneira, lembramo-nos das reflexões de Candido (1995) acerca do aspecto humanizador do texto literário.

O leitor é apresentado como uma figura que expõe as suas sensibilidades diante da leitura literária, caracterizando, assim, o papel humanizador no que se refere à formação do ser. Desse modo, acreditamos que:

A literatura corresponde a uma necessidade universal que deve ser satisfeita sob a pena de multilar a personalidade, porque pelo fato de dar forma aos sentimentos e a visão de mundo ela nos organiza, nos libera de caos e portanto nos humaniza. Negar a fruição literária é mutilar a nossa humanidade [...] (CANDIDO, 1995, p.186).

É por esse caminhar que o ato da leitura apresenta a função de humanizar o sujeito leitor por meio da experiência de leitura, impulsionando-o a descobertas e a um conhecimento crítico e sensível. Os $63,15 \%$ que responderam NÃO justificaram da seguinte maneira: M08 - "Não muito, porque não tenho prática de ler tanto", M06 "Não, porque nem toda hora é pra ler algo", M09 - "Não gosto". Tais justificativas nos faz pensar no modo como a leitura está sendo mediada em sala de aula, bem como se esses sujeitos tiveram acesso a livros, tanto no âmbito escolar quanto no ambiente familiar.

O segundo gráfico está centrado na leitura de poesia. Desse modo, perguntamos aos colaboradores se gostavam de ler poesia. Segue a ilustração abaixo:

\section{Gráfico 2 Leitores de poesia}

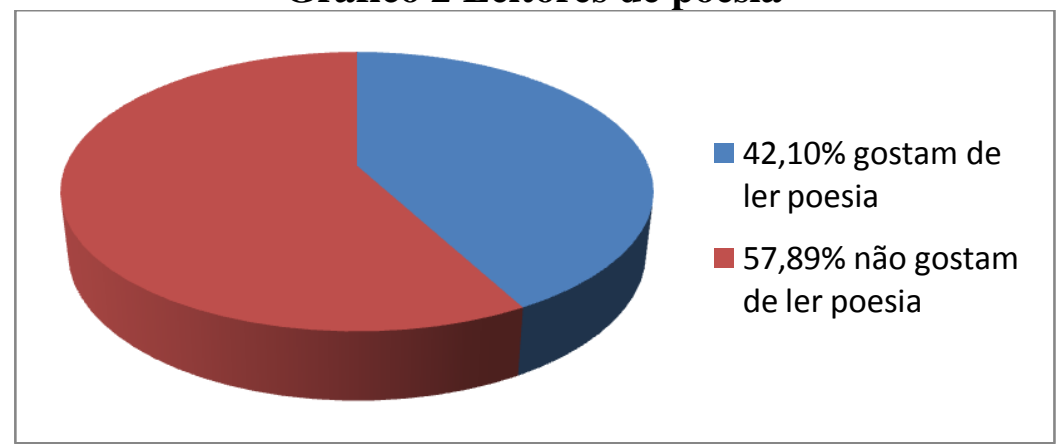

${ }^{12} \mathrm{O}$ resultado dos cálculos percentuais se deu a partir da regrade três simples, cujo valor total de um dado número é multiplicado pela fração com denominador a 100\%. Informações disponíveis em: http://www.brasilescola.com/matematica/porcentagem-utilizando-regra-tres.htm 
Conforme o gráfico, 42,10\% dos estudantes lê poesia. Alguns participantes da experiência de leitura literária que disseram "SIM" para a questão 02, alegando as seguintes considerações:

M01: Sim, porque a poesia é romântica.

M03: Sim, porque acho bonitas, legais.

M04: Sim, porque é bem legal.

M07: Sim, porque elas são bonitas.

M10: Sim, porque é bom.

M13: Sim, porque é muito interessante.

A partir destes comentários, percebemos um conhecimento prévio de poesia centrada no senso comum, em que o poema é definido como um texto bonito que apresenta uma temática amorosa "porque a poesia é romântica". Já outros participantes comentaram a respeito de suas disposições estruturais e discursivas, argumentando que a poesia é bonita e interessante. A maioria dos $57,89 \%$ dos estudantes que marcou NÃ̂O para a questão cinco (05) não justificou, no questionário, o porquê de não gostar de poesia; no entanto, dois alunos da experiência escreveram as seguintes considerações: M06: "não tenho interesse por poesia"; M09: "acho chato".

A questão 03 (Gosta de ler em voz alta? Por quê?) coloca os estudantes na perspectiva de leitores que leem em voz alta. Para que os dados sejam organizados de maneira significativa, iremos esboçá-los por meio de um gráfico.

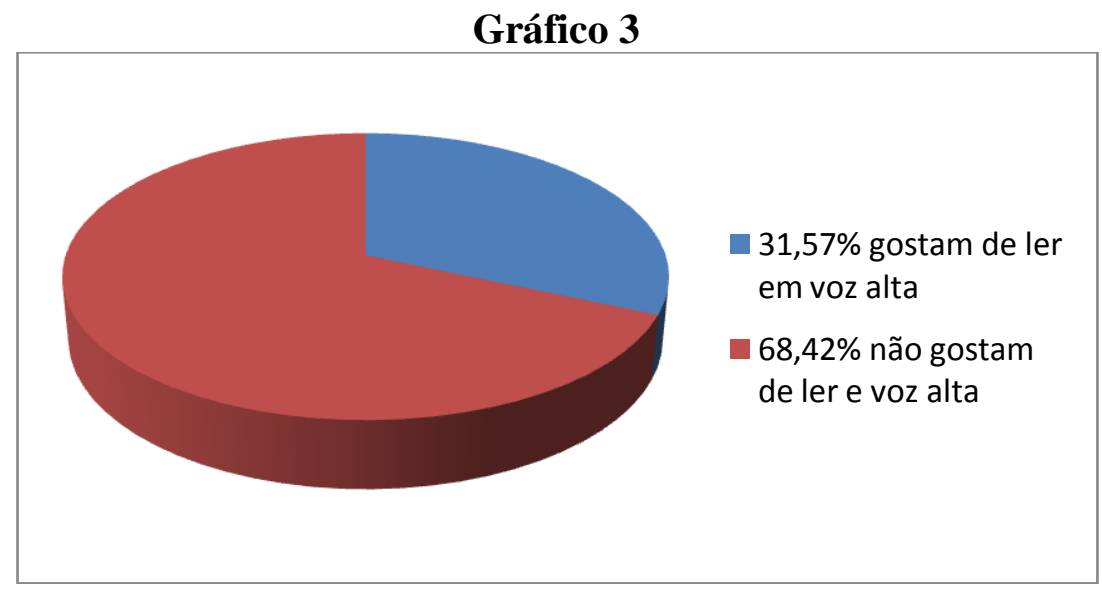

Dessa forma, os dados revelaram que $31,57 \%$ gostam de ler em voz alta, justificando da seguinte maneira:

M02: Sim, porque me sinto melhor e quero que todos ouçam.

M03: Sim, não sei. Já é um costume

M04: Sim, para que os ouvintes entendam melhor.

M05: Sim, porque posso compartilhar o que estou aprendendo.

M07: Sim, porque melhora a sua leitura e o seu português.

M13: Sim, porque acho melhor.

A partir dos comentários dos discentes, percebemos algumas colocações pertinentes a respeito da importância da leitura em voz alta, tais como: M02 "Sim, porque me sinto melhor e quero que todos ouçam" e M04 "sim, para que os ouvintes entendam melhor". A preocupação com a compreensão com os ouvintes em sala de aula 
é um dos pontos mais discutidos no questionário. Dessa forma, a leitura oral permite uma apreensão melhor do texto.

No entanto, antes da leitura oral, seria necessária uma leitura silenciosa, uma vez que o leitor consiga atingir a compreensão. Esse recurso estratégico permite ao estudante o primeiro contato com o texto. Nesse sentido, o discente descobriria o seu próprio ritmo de leitura, a fim de atingir o objetivo da compreensão do poema. Dessa forma,

a leitura em voz alta não passa de um tipo de leitura que permite cobrir algumas necessidades, objetivos ou finalidades de leitura. A 'preparação' da leitura em voz alta, permitindo que as crianças façam uma leitura individual e silenciosa, antes da oralidade, parece-me um recurso que deveria ser utilizado (SOLÉ, 1998, p.99).

Os $68,42 \%$ justificaram que não gostam de ler em voz alta. Dessa forma, alguns destes discentes argumentaram da seguinte maneira: M07: "Não, porque dá vergonha", M08: "Não, porque não gosto de incomodar ninguém" e M11: "Não, porque gosto de meditar a leitura".

A partir das reflexões dos dados do questionário de sondagem, constatamos alguns pontos do conhecimento prévio dos colaboradores da experiência literária, como, por exemplo, relacionar o gênero lírico à temática romântica. Desse modo, elaboramos a antologia "Haicai de Alice Ruiz" para criar uma ruptura a este senso comum em torno da poesia.

No contexto da leitura de poesia em sala de aula, percebemos o interesse de alguns discentes em experimentar a leitura em voz alta, a fim de compartilhar a compreensão do texto com a turma. A partir dos dados do questionário, a maioria dos estudantes da turma do $1^{\circ}$ ano B não experimentou a leitura oral em classe. Dessa forma, pensamos em uma estratégia metodológica calcada na leitura oral e na socialização da leitura em sala de aula. Estas estratégias contribuíram para a incursão dos colaboradores no texto literário.

Dessa forma, a leitura dos haicais foi realizada na quarta-feira, dia 29 de abril de 2015, na sala de aula da turma do $1^{\circ}$ ano B. Nesta ocasião, iríamos iniciar "Haicai de Alice Ruiz".

Distribuímos a antologia de haicais, solicitando uma leitura silenciosa. Após o primeiro momento da leitura, o estudante M17 comentou que "o haicai é uma poesia bem curtinha". Posteriormente, perguntamos, ao mesmo discente, se gostou da leitura da antologia. Com entusiasmo, nos respondeu que SIM. Nesse contexto, iniciamos a leitura oral. Alguns alunos da turma leram os haicais da antologia; no entanto, o estudante M11 leu como se estivesse cantando rap ${ }^{13}$, agradando a turma. Dessa forma, M11 agrupou $^{14}$ os seguintes haicais:

\footnotetext{
${ }^{13}$ No artigo Reflexão em torno do movimento Hip Hop, Nunes e Silva (2007) discutem algumas reflexões acerca do Rap. Surgido nos EUA, precisamente no Bronx, em Nova York, este gênero artístico e urbano expressa algumas manifestações populares, uma vez que relata, por meio de rimas improvisadas e versos curtos, questões de grupos descriminalizados, como, por exemplo, jovens negros, a pobreza e a injustiças sociais.

${ }^{14}$ Este dado foi coletado através da transcrição do áudio de nossa pesquisa.
} 


M11: Tocadas pelo vento
As árvores dançam
Primeira estrela
Ainda menor
Ainda menor que ela
Último passarinho
Moça no campo
Atraindo beija flor
Vestido colorido
Maré cheia
A garça de pedra
em pedra
Sem molhar os pés
E agora?
Pipa perdida
Para a árvore seca
Primeira folha
Folha ao vento forte
Vento!
Vento arranca as folhas
Folhas na escada
Não sobem nem descem
Folhas na escada
Não sobem nem descem

A leitura de M11 é significativa para pesquisa, visto que podemos acompanhar o processo de experiência estética. De acordo com Jauss (2012), quando a leitura segue da poiesis (recepção do texto) para aisthesis (fruição estética), o leitor passa a assumir um papel de produtor, uma vez que o sujeito da recepção experimenta os diversos efeitos, a partir da interação texto-leitor, dos mais variados recursos estéticos do texto literário, a fim de se apropriar destes elementos para compor algo novo. Nesse contexto, o discente M11 - por meio da leitura oral - selecionou os haicais de Alice Ruiz por meio da semelhança sonora e rítmica para compor um texto novo.

O andamento da leitura de M11 está calcado no rap. Esta configuração parte do pressuposto de que as vivências e as experiências de mundo se refletem e se projetam na leitura literária. Dessa forma, este conhecimento prévio reverberou em M11 na sua leitura oral.

Nesse sentido, a leitura silenciosa e oral pode contribuir de modo significativo para o estudante, uma vez que os instiga a perceber os valores estéticos da musicalidade no poema. Dessa forma, o estudante M11, ao descobrir estes elementos estéticos, montou um novo texto a partir de fragmentos poéticos dos haicais de Alice Ruiz.

Posteriormente, o aluno M13 se manifestou, lendo o haicai "Basta um galhinho/ E vira trapezista/ O passarinho". Em seguida, comentou que gostou muito da rima e da ilustração. A partir dessa observação em torno da ilustração, solicitamos para 
os discentes que escolhessem um haicai não ilustrado da antologia para desenhar uma imagem que o texto lhes sugerisse. Dessa forma, distribuímos papel A4 e lápis de cores para turma do $1^{\circ}$ ano B. Ressalvamos que nenhum dos estudantes teve contanto com os livros ilustrados e que houve a leitura oral e o compartilhamento das discussões dos haicais no semicírculo. Posteriormente, recolhemos as ilustrações feitas pelos estudantes e agradecemos pela participação de todos.

Para os limites deste artigo, selecionamos quatro (04) ilustrações. Estes dados são significativos porque demonstram - de maneira subjetiva - como o leitor real recepciona o texto poético e o coaduna com as suas vivências e experiências de mundo. Seguem os desenhos abaixo:

Figura 1- desenho de M01

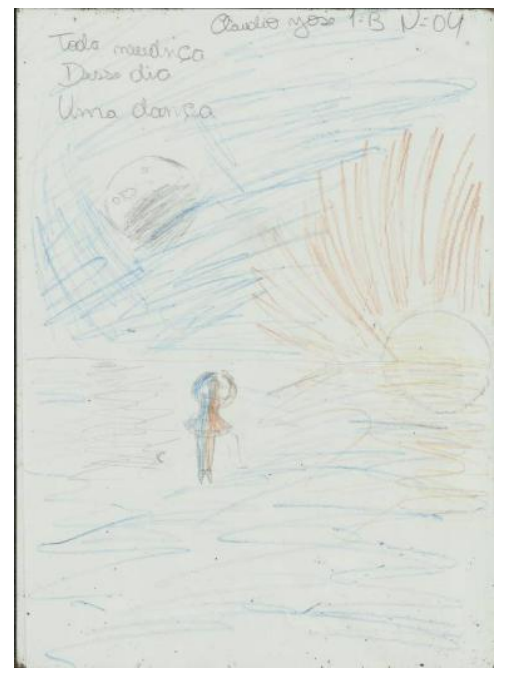

Fonte: dados da pesquisa
Figura 2 - desenho de M17

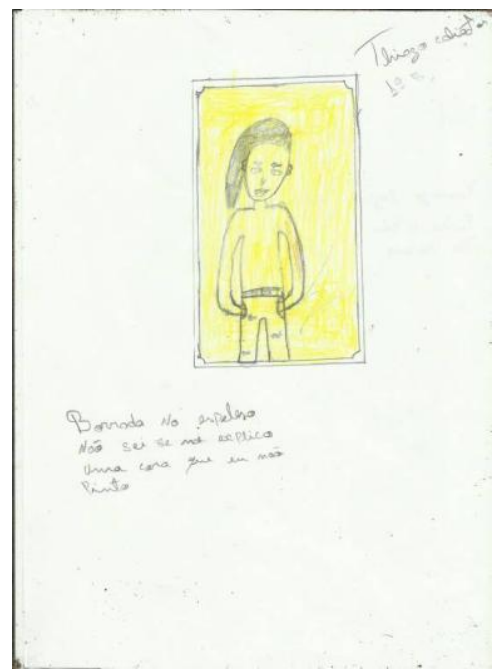

Fonte: dados da pesquisa

No primeiro desenho, M01 recepcionou o haicai "Toda mudança/desse dia/uma dança" e percebeu que a expressão "mudança" está relacionada com a "dança", uma vez que representou o ritmo da dança por meio da bailarina e a mudança através da transição da noite para dia. As cores das ambientações (azul e vermelho) refletem na bailarina, reforçando a ideia que as disposições anímicas do sujeito lírico do haicai são influenciadas por meio do movimento do tempo (noite e dia).

No segundo desenho, M17 recepcionou o haicai "Borrada no espelho/não sei se me explico/uma cara que eu não pinto" e desenhou um garoto se olhando no espelho, como se o próprio sujeito lírico estivesse observando a efemeridade do tempo. A cor amarela borrada no espelho pode fazer uma alusão à passagem do tempo, em que o eu lírico contempla a sua própria mudança ao longo do tempo. 
Figura 3: desenho de M11

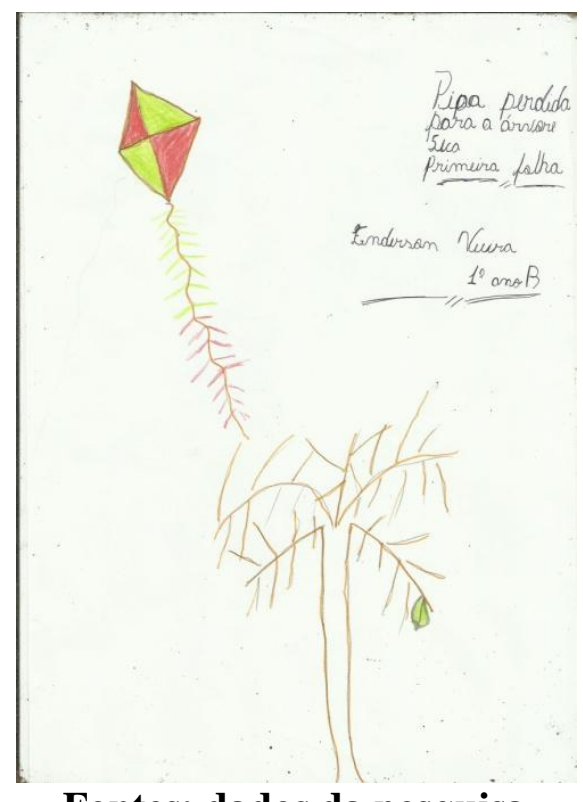

Fontes: dados da pesquisa
Figura 4: desenho de M13

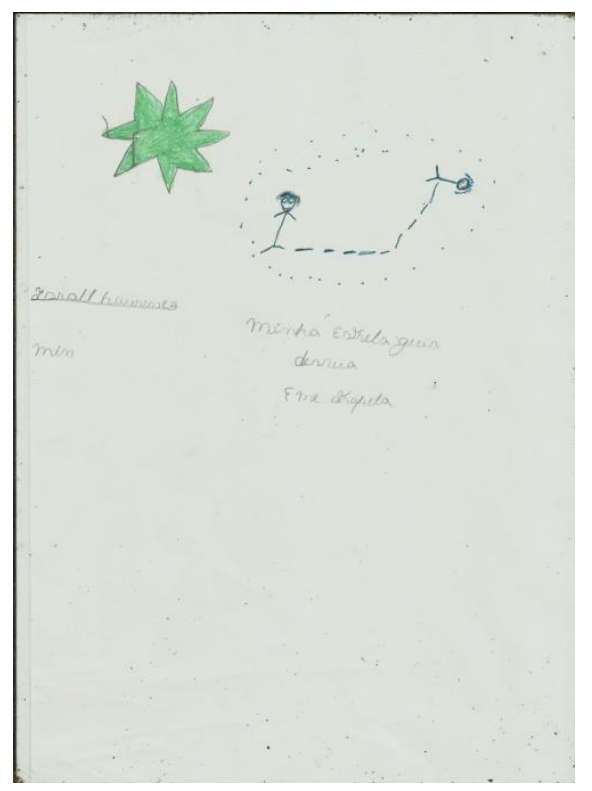

Fontes:dados da pesquisa

O aluno M11 recepcionou o haicai "Pipa perdida/para a árvore seca/primeira folha". Nesta ilustração, o colaborador/discente se pôs no lugar do eu lírico do poema para flagrar a imagem da chegada da estação do outono, uma vez que desenhou uma folha em uma árvore seca. Ressalva-se que as cores que o aluno inferiu na leitura se refere a um tom alaranjado e amarelado, o que pode fazer uma menção ao período as cores do outono vivenciadas pelo aluno e a melancolia da referida estação.

Já M13 ilustrou o haicai "Minha estrela guia/desvia/e me atropela". Neste desenho, o colaborador desenhou alguns traçinhos em volta da personagem para expressar a ideia de movimento do haicai, já que este eu lírico do referido poema foi guiado pela estrela.

Na próxima seção, fizemos algumas considerações acerca da experiência de leitura com os haicais de Alice Ruiz.

\section{Considerações finais.}

Elaborar uma metodologia de ensino calcada na experiência estética e na leitura dos haicais de Alice Ruiz foi um desafio, uma vez que exigiu um trabalho concomitante entre a prática pedagógica e a teoria literária. Nesse sentido, o nosso fazer pedagógico, que teve como base a preocupação com a formação do leitor literário em sala de aula, permitiu ao leitor-aluno uma experiência estética, já que os discentes relacionaram os seus próprios contextos de mundo com algumas questões estético/temáticas do poema. A recepção do haicai de Alice Ruiz na turma do $1^{\circ}$ ano "B" se deu a partir da interação texto-leitor, sendo que a metodologia e as estratégias de leituras adotadas no nosso fazer pedagógico contribuíram para a incursão dos sujeitos leitores no texto poético. Desse modo, a estratégia de desenhar as imagens poéticas dos haicais para compartilhá-las em seguida na sala de aula foi significativa, já que instigou o debate entre os alunos em uma tentativa de construir uma apreensão geral dos haicais lidos na experiência. 
No contexto da compreensão de leitura dos haicais, observamos que alguns discentes participaram da produção de efeitos e sentidos de maneira satisfatória, o que configura em uma experiência estética no âmbito escolar. A partir desse viés, percebemos um deslumbramento e uma vibração em torno de alguns recursos estéticos na sala de aula, tais como: métrica, rima e ritmo. Este encantamento corroborara o prazer estético (aisthesis). Já a poiesis, que, de acordo com Jauss (1979), é a consciência criadora do leitor, é uma das categorias da experiência estética que foi evidenciada em nossa pesquisa. Alguns discentes, a título de exemplo, se apropriaram dos haicais de Alice Ruiz para produzir os seus próprios textos, como, por exemplo, o rap cantado em classe e as ilustrações feitas pelos alunos. Por meio das discussões em sala de aula, observamos a reverberação (kathersis) do texto literário no leitor, uma vez que houve uma mobilização em torno de algumas questões estético-temáticas presentes nos haicais de Alice Ruiz, que favoreceram a constituição de novas perspectivas sobre as suas próprias experiências/vivências de mundo, os seus valores, os seus modismos e as suas concepções ideológicas, como, por exemplo, a desconstrução do senso comum do poema e a leitura perceptiva dos haicais do colaborador M11.

Portanto, o nosso fazer pedagógico contribuiu de maneira satisfatória para a atitude do docente, visto que o professor/pesquisador seguiu uma postura dialógica ao longo dos encontros em sala de aula, mediando, portanto, o texto, as leituras, as múltiplas interpretações e os debates centrados nos haicais de Alice Ruiz no âmbito escolar.

\section{Referências}

AGUIAR, Vera Texeira de; BORDINI, Maria da Glória. Literatura: a formação do leitor - alternativas metodológicas. Porto Alegre: Mercado Aberto, 1993.

ANDRADE, Carlos; GEBARA Ana Elvira Luciano; GUARANHA, Manuel Francisco; CARDOSO, Diogo Souza. Haicai, Poetrix e Microconto: discurso literário em nanopoéticas. São Paulo: Terra Editora, 2012.

COHEN, Jean. Estrutura da linguagem poética. Tradução: Álvoro Loerencini e Anne Arnichand. São Paulo, Cultrix, 1974.

CANDIDO, Antonio. O direito à literatura. In: Vários escritos. 3 ed. São Paulo: Duas cidades, 1995.

CRUZ, Marília de Alexandria; TINOCO, Robson Coelho. O feminino sob(re) uma sociedade masculina: traços poéticos de Alice Ruiz. Grafhos. João Pessoa, vol. 14, $\mathrm{n}^{\circ}$ 2, 2012 | UFPB/PPGL | ISSN 1516-1536. p. 164-172.

JAUSS, Hans Robert. A história da literatura como provocação à teoria literária. Tradução: Sérgio Tellaroli. São Paulo: Ática, 1994.

O prazer estético e as experiências fundamentais da poiesis, aisthesis $e$ kathersis. In: LIMA, Luiz Costa. (Sel. Coord. Trad.) A literatura e o leitor: textos de Estética da Recepção. Rio de Janeiro: Paz e Terra, 1979, p.63-80.

MARQUES, Helena Maria Medina. A lírica de Alice Ruiz S.: Imagens poéticas, Mito e Sociedade: 2012. 187 f. Dissertação do Mestrado em Letras - Universidade Estadual do Oeste do Paraná. Cascavel. 2012. 
MOREIRA, Herivelto; CALEFFE, Luiz Gonzaga. Metodologia da pesquisa para o professor pesquisador. Rio de Janeiro: DP\&A, 2006.

MURGEL, Ana Carolina Arruda de Toledo. "Navalhanaliga": a poética feminista de Alice Ruiz. Tese (Doutorado em História). Instituto de Filosofia e Ciências Humanas da Universidade Estadual de Campinas, 2010.

Encantando versos: a produção musical de Alice Ruiz. Texto integrante dos Anais do XVII Encontro Regional de História - O lugar da História. ANPUH/SPUNICAMP. Campinas, 6 a 10 de setembro de 2004. Cd-rom.

NUNES, Marco Antônio Oliveira; SILVA, Lúcia Helena Oliveira. Reflexão em torno do movimento Hip Hop. Revista afro atitudeanas, v. 2, n. 1, 2007.

PINHEIRO, Hélder. Poesia na sala de aula. 3. ed. ampliada. Campina Grande: Bagagem, 2007.

ROUXEL, A.. Aspectos metodológicos do Ensino de Literatura. In: DALVI, M. A. REZENDE, N. L. de, JOVER-FALEIROS, R. (org.). Leitura de literatura na escola. São Paulo: Parábola, 2013.

RUIZ S., Alice. Conversa de passarinhos. São Paulo: Iluminuras, 2008.

. Dois em um. São Paulo: Iluminuras, 2008.

. Jardim de Haijin; ilustrações Fê. São Paulo: iluminuras, 2010.

. Outro silêncio. São Paulo: iluminuras, 2015.

SOLÉ, Isabel. Estratégias de leitura. Tradução: Cláudia Schilling - 6. edição. Porto Alegre: ArtMed, 1998.

STAIGER, Emil. Conceitos fundamentais da poética. Tradução: Celeste A. Galeão, Rio de Janeiro: Tempo Brasileiro, 1975.

Recebido em 31 de junho de 2018

Aceito em 22 de novembro de 2018 